\title{
Impact en omvang van afwijkende werktijden in Nederland
}

\author{
Marianne van Zwieten, John Klein Hesselink, Irene Houtman
}

In een ander artikel van dezelfde auteurs in dit themanummer is nagegaan wat bekend is vanuit de literatuur over afwijkende werktijden. ${ }^{\mathrm{I}}$ De literatuur laat zien dat overwerk, het werken in ploegendienst en 's nachts werken samenhangen met diverse negatieve gezondheidsgevolgen (zoals hart- en vaatziekten en maag-darmklachten). Het is daarom relevant om de omvang van het werken op afwijkende tijden in de Nederlandse arbeidssituatie na te gaan aan de hand van empirische gegevens vanuit landelijk steekproefonderzoek.

Onder normale werktijden wordt in Nederland veelal een werkweek verstaan die loopt van maandag tot en met vrijdag, waarbij overdag ongeveer acht uur wordt gewerkt. De afwijkingen van het werken op reguliere tijden betreffen altijd de duur van het werk en/of het moment waarop wordt gewerkt. De verschillende vormen van afwijkende werktijden kunnen diverse gevolgen hebben voor werknemers. Deze kunnen positief zijn, zoals het beter kunnen combineren van werk- en zorgtaken, maar de gevolgen kunnen ook nadelig zijn voor de werknemer. Niet alleen het sociale leven kan nadelig worden beïnvloed, bijvoorbeeld doordat er door overwerken minder tijd is voor sociale activiteiten en het bij onregelmatige (nacht)diensten lastiger is om met vrienden of familie af te spreken. Het werken op afwijkende werktijden kan ook allerlei nadelige gevolgen hebben voor de gezondheid.

Dit artikel gaat eerst kort in op de samenhang tussen afwijkende werktijden en gezondheid en welzijn van Nederlandse werknemers. Dit gebeurt aan de hand van gegevens van de Nationale Enquête Arbeidsomstandigheden (NEA). ${ }^{2}$ De NEA is een grootschalige jaarlijkse enquête onder

Drs. M.H.J. van Zwieten is onderzoekster. Dr. D.J. Klein Hesselink is onderzoeker. Dr. I.L.D. Houtman is senior onderzoekster. Allen zijn verbonden aan TNO, Work \& Health, Hoofddorp.

\section{CORRESPONDENTIEADRES}

E-mail: irene.houtman@tno.nl.

\section{SAMENVATTINC}

Veel werknemers in Nederland werken op afwijkende tijden, dat wil zeggen op andere tijden dan van maandag tot en met vrijdag, waarbij overdag ongeveer acht uur wordt gewerkt. In dit artikel wordt aan de hand van de Nationale Enquête Arbeidsomstandigheden (NEA) beschreven in hoeverre afwijkende werktijden zich in Nederland recentelijk hebben ontwikkeld en in hoeverre ze anno 20 Io voorkomen. Ook wordt er een vergelijking gemaakt tussen afwijkende werktijden in Nederland en Europa (EWCS).

Gegevens van de NEA 2010 wijzen uit dat ruim een kwart van de Nederlandse werknemers structureel overwerkt, terwijl nagenoeg een kwart regelmatig's avonds of 's nachts werkt. Verder geeft $16 \%$ aan in ploegendienst te werken. Het percentage Nederlandse werknemers dat op afwijkende werktijden werkt, is in de afgelopen jaren redelijk stabiel. Wel verschilt Nederland enigszins van gemiddeld Europa, vooral omdat vrouwen vaker parttime werken.

\section{SUMMARY}

Impact and extent of non-standard working hours in the Netherlands

Many employees in the Netherlands have non-standard working hours; standard working hours being about eight hours a day, at day time, on Monday to Friday. In this article trends in non-standard hours and the situation in 2010 are described, based on data from the Netherlands Working Conditions Surveys (NWCS/NEA) 2005-20Io. In addition, a comparison is made between working non-standard hours in the Netherlands and other European countries using data from the European Working Conditions Survey (EWCS).

Data from the NWCS 20 Io indicate that about a quarter of Dutch employees works overtime structurally. About a quarter of the population regularly works in the evenings and at night and I6\% is involved in shift work. About 30\% works regularly in the weekends.

The percentage of workers on overtime, working in the evenings, weekends, at night or in shifts has remained relatively stable over the years.

There are differences between the Netherlands and other European countries. Women more often work in part-time jobs.

werknemers in Nederland waarin onder meer wordt gevraagd naar arbeidsomstandigheden, arbeidsinhoud, arbeidsverhoudingen en arbeidsvoorwaarden. Op basis van de NEA 20Io is vervolgens nagegaan wat kenmerken zijn van werknemers die werken op afwijkende werktijden en WERKTIJDEN, NEDERLAND, IMPACT, in welke sectoren deze verschillende vormen van afwijkende werktijden het meest voorkomen.
VÓÓRKOMEN,

TRENDS 
Naast een beschrijving van de huidige stand van zaken, is aan de hand van gegevens van de NEA 2005-2010 de ontwikkeling in de tijd gevolgd in het aantal werknemers in Nederland dat op afwijkende werktijden werkt. Voor een vergelijking van Nederland met Europa wordt gebruik gemaakt van gegevens van de European Working Conditions Survey (EWCS). ${ }^{3}$

De volgende onderzoeksvragen worden in dit artikel beantwoord:

1. Wat is de samenhang tussen afwijkende werktijden en gezondheid en welzijn van Nederlandse werknemers?

2. Hoeveel en welke werknemers in Nederland werken op afwijkende tijden?

3. Wat zijn de trends in het aantal personen dat op afwijkende tijden werkt?

4. Hoe verhoudt Nederland zich tot Europa wat betreft het werken op afwijkende werktijden?

\section{GEZONDHEID EN WELZIJN VAN \\ NEDERLANDSE WERKNEMERS}

Aan de hand van de NEA-gegevens van 2010 is nagegaan wat de samenhang is tussen afwijkende werktijden en gezondheid en welzijn van Nederlandse werknemers. Uit tabel I blijkt dat werknemers die structureel overwerken of in ploegendienst werken, vaker aangeven dat ze emotioneel uitgeput zijn en vaker overgewicht/obesitas hebben. Daarnaast geven ze, net als werknemers die 's avonds of 's nachts werken, vaker aan dat ze te maken hebben met arbeidsongevallen, vaker familie- of gezinsactiviteiten verwaarlozen door het werk, en werkzaamheden te missen of te verwaarlozen door familie- en gezinsverantwoordelijkheden. Het werken op afwijkende werktijden lijkt dus ook negatieve gevolgen te hebben voor de Nederlandse werknemer. Van belang is daarom om na te gaan hoe vaak het werken in ploegendienst, 's avonds of 's nachts werken en overwerken in Nederland eigenlijk voorkomt.

I Ruim een kwart van de Nederlanders werkt structureel over.

I Nagenoeg een kwart van de Nederlandse werknemers werkt 's avonds of 's nachts.

I Zo'n I6\% van de werknemers in Nederland werkt in ploegendienst.

I Trends in afwijkende werktijden in Nederland zijn redelijk stabiel.

I Vergeleken met Europa werken Nederlanders alleen wat minder uren per week. Dit komt vooral door het relatief grote (met name vrouwelijke) aandeel deeltijders.

\section{AFWIJKENDE WERKTIJDEN}

IN NEDERLAND EN EUROPA

Uit de NEA-gegevens van 2010 blijkt dat Nederlandse werknemers volgens hun contract gemiddeld iets minder dan 3I uur in de week werken, verdeeld over ruim vier dagen. ${ }^{2}$ In de periode 2005 tot 20 Io is er nagenoeg geen verschil in omvang van het contractuele dienstverband en het gemiddeld aantal werkdagen per week (NEA 2005-20I0).

Wanneer de werktijden in Nederland worden vergeleken met die in Europa, blijkt dat de Nederlandse werknemer relatief weinig uren werkt. Gemiddeld genomen werken werknemers in Nederland 4,5 uur minder dan de gemiddelde Europese werknemer (EWCS, 2005). Dit hangt samen met het grote (en stijgende) aandeel deeltijders in Nederland. Uit gegevens van Eurostat blijkt dat het percentage deeltijders in Nederland is gestegen van $4 \mathrm{I} \%$ in 2000 naar $48 \%$ in 2009 , terwijl het gemiddelde percentage voor Europa in $20092 \mathrm{I} \%$ betreft. Het gemiddelde aantal uren werk per week in de belangrijkste baan van fulltime werknemers in Nederland verschilt in 2010 nauwelijks van het gemiddelde van Europa: 39,5 in Nederland versus 39,7 in EU-27 en 39,4 in EUI5 (Eurostat, Labour Force Survey).

\section{Overwerk}

Bijna driekwart (73\%) van de werknemers in Nederland geeft in 2010 aan op zijn minst incidenteel overwerk te verrichten (zie tabel 2). Ruim een kwart (27\%) geeft aan structureel overuren te hebben gemaakt. In de periode 2005-20I0 is het percentage werknemers dat aangeeft over te werken nagenoeg gelijk gebleven. Nederlandse werknemers maken naast de contractuele uren gemiddeld 3,4 overuren. Gemiddeld werkt de Nederlandse werknemer inclusief overwerk 34 uur per week. Wanneer daar ook reistijd en pauzes bij worden opgeteld, wordt per werkdag negen uur aan werk besteed. Het zijn vooral mannen die structureel overwerken en gemiddeld de meeste overuren maken.

In de 'European Working Conditions Survey (EWCS) is werknemers gevraagd naar het aantal keer per maand dat meer dan tien uur op een dag wordt gewerkt (tabel 3). Bij Nederlandse werknemers ligt dit percentage enigszins hoger dan bij de gemiddelde Europese werknemer (respectievelijk $39 \%$ en $32 \%$ in 20I0). Dit verschil wordt vooral veroorzaakt door het grote percentage mannelijke werknemers in Nederland dat aangeeft minstens één keer per maand meer dan tien uur op een dag te werken. Het percentage vrou- 


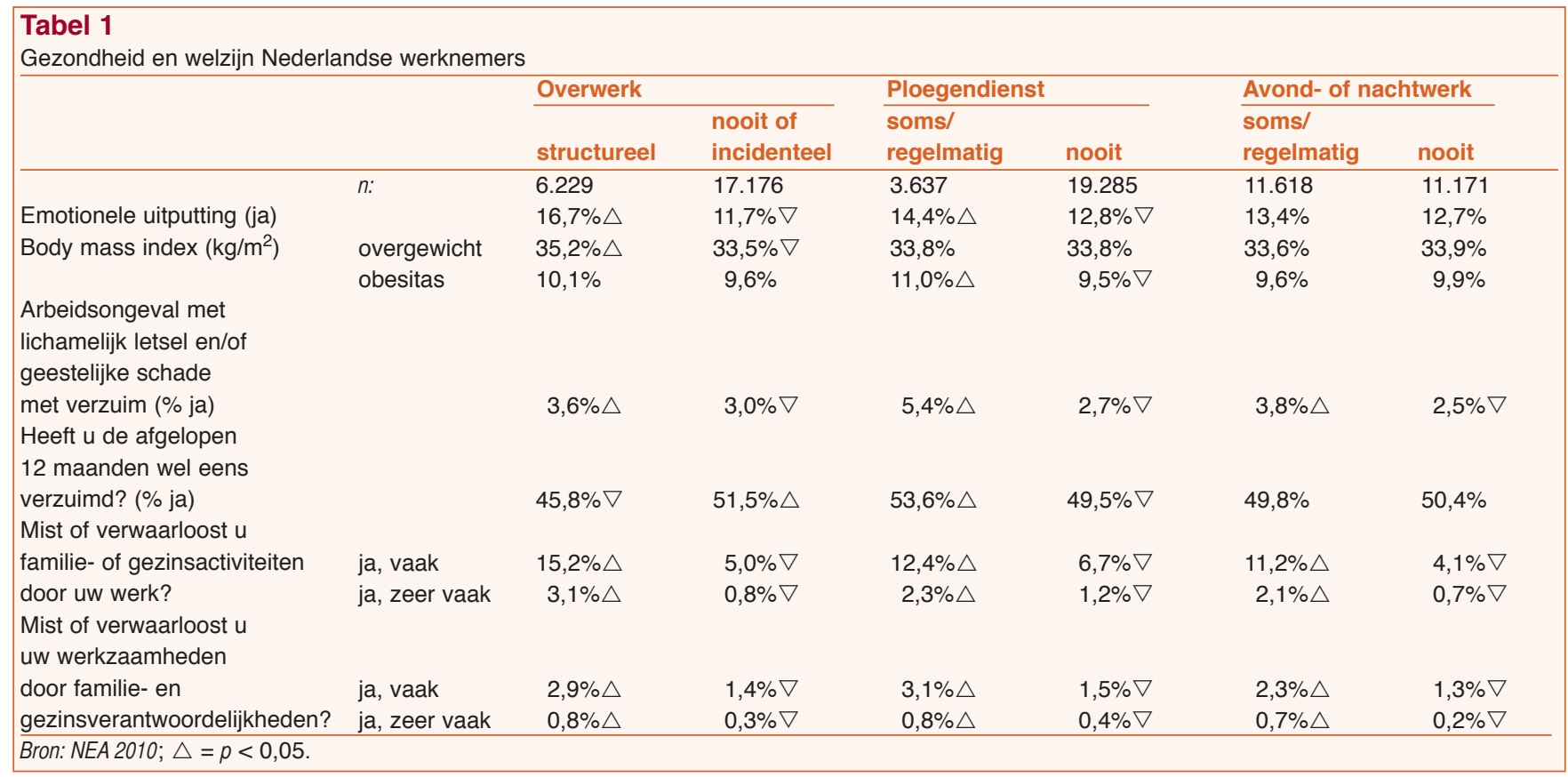

welijke werknemers dat overwerkt, verschilt nauwelijks tussen Nederland en Europa.

\section{Avond-/nachtwerk en weekendwerk}

Bijna een kwart (24\%) van de werknemers geeft in 2010 aan het afgelopen jaar regelmatig 's avonds of 's nachts te hebben gewerkt, terwijl nagenoeg een derde (30\%) regelmatig in het weekend heeft gewerkt (zie tabel 4). Het percentage werknemers dat aangeeft 's avonds of 's nachts te werken, is in de periode 2005-20Io nagenoeg gelijk gebleven. Dit geldt ook voor werken in het weekend. Meer mannen dan vrouwen werken 's avonds, 's nachts of in het weekend. Dit werken op afwijkende momenten gebeurt met name in de jongste leeftijdscategorie (I5-24 jaar). Vooral laag en middelbaar opgeleiden geven aan in het weekend te werken, terwijl 's avonds of 's nachts werken vooral door middelbaar en hoogopgeleiden gebeurt.

In zowel Nederland als Europa is het percentage werknemers dat in 2010 in de EWCS aangeeft minstens één keer per maand in het weekend te werken, ongeveer 50\% (zie tabel 5). Ook het deel van de werknemers dat aangeeft minstens één keer per maand 's nachts te werken verschilt nauwelijks tussen Nederland en Europa (respectievelijk I $5 \%$ en $17 \%$ in 2010).

\section{Ploegendienst}

Van de Nederlandse werknemers geeft I6\% aan in ploegendienst te werken, $13 \%$ doet dit regelmatig (zie tabel 6). Dit percentage is nagenoeg gelijk in de periode 2005-20Io. 's Avonds, 's nachts

\begin{tabular}{|lllllll|}
\hline $\begin{array}{l}\text { Tabel } 2 \\
\text { Trends in overwerk in Nederland }\end{array}$ & & & & & & \\
\hline & 2005 & 2006 & 2007 & 2008 & 2009 & 2010 \\
\hline Overwerken (\% ja) & 72 & 73 & 73 & 74 & 74 & 73 \\
Structureel overwerken (\% ja) & 28 & 29 & 28 & 28 & 26 & 27 \\
Incidenteel overwerken (\% ja) & 45 & 45 & 46 & 46 & 48 & 47 \\
Aantal overuren per week & 3 & 4 & 4 & 4 & 3 & 3 \\
\hline Bron: NEA 2005-2010. & & & & & & \\
\hline
\end{tabular}

\begin{tabular}{|c|c|c|c|}
\hline \multicolumn{4}{|c|}{$\begin{array}{l}\text { Tabel } 3 \\
\text { Trends in overwerk in Nederland en Europa }\end{array}$} \\
\hline & 2000 & 2005 & 2010 \\
\hline \multicolumn{4}{|c|}{$\begin{array}{l}\text { Minstens één keer per maand meer dan } \\
10 \text { uur per dag werken }(\%)\end{array}$} \\
\hline Nederland & 36 & 42 & 39 \\
\hline Mannen & 48 & 54 & 54 \\
\hline Vrouwen & 19 & 26 & 21 \\
\hline EU-15 & 33 & 35 & 32 \\
\hline Mannen & 42 & 44 & 39 \\
\hline Vrouwen & 22 & 23 & 22 \\
\hline
\end{tabular}

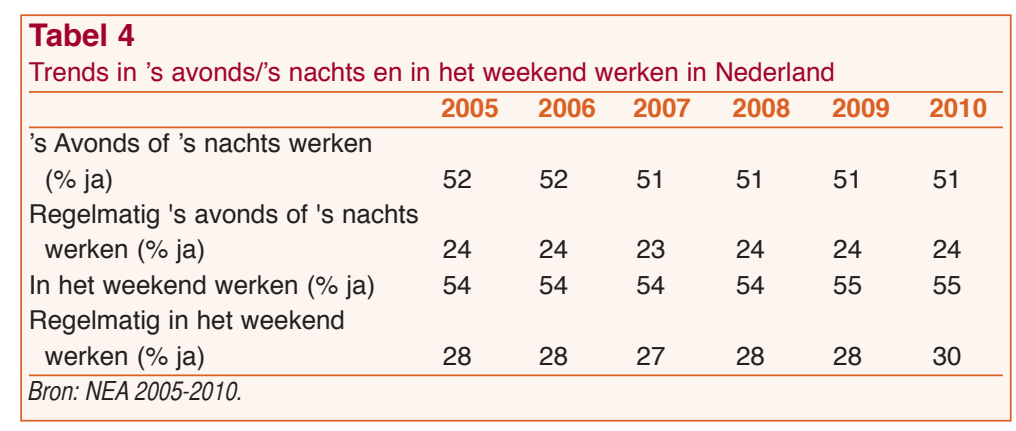

en in het weekend werken vindt veelal plaats in het kader van ploegendienst. Van de werknemers die in 2010 in het weekend hebben gewerkt, werkt ruim een derde $(37 \%)$ ook regelmatig in ploegendienst. Van de werknemers die regelmatig 
's avonds of 's nachts hebben gewerkt, werkt $45 \%$ regelmatig in ploegendienst. Vooral in de jongste leeftijdsgroep wordt in ploegendienst gewerkt.

\section{Tabel 5}

Trends in 's avonds/'s nachts en in het weekend werken in Nederland en Europa

\begin{tabular}{llll}
\hline & 2000 & 2005 & 2010 \\
\hline Minstens één keer per maand & & & \\
in het weekend werken (\%) & 45 & 48 & 47 \\
Nederland & 47 & 50 & 53 \\
$\quad$ Mannen & 42 & 45 & 41 \\
$\quad$ Vrouwen & 54 & 47 & 51 \\
EU-15 & 57 & 45 & 54 \\
$\quad$ Mannen & 51 & 51 & 48 \\
$\quad$ Vrouwen & & & \\
Minstens één keer per maand 's nachts werken, & & & \\
ten minste twee uur tussen 22:00 uur en 05:00 uur (\%) & & 19 & 15 \\
Nederland & 18 & 24 & 19 \\
$\quad$ Mannen & 23 & 11 & 12 \\
$\quad$ Vrouwen & 11 & 18 & 17 \\
EU-15 & 18 & 23 & 21 \\
$\quad$ Mannen & 22 & 13 & 13 \\
$\quad$ Vrouwen & 11 & & \\
\hline Bron: EWCS; http://www.eurofound.europa.eu/surveys/smt/ewcs/results.htm. & & & \\
\hline
\end{tabular}

\begin{tabular}{|c|c|c|c|c|c|c|}
\hline \multicolumn{7}{|c|}{$\begin{array}{l}\text { Tabel } 6 \\
\text { Trends in ploegendienst in Nederland }\end{array}$} \\
\hline & 2005 & 2006 & 2007 & 2008 & 2009 & 2010 \\
\hline In ploegendienst werken (\% ja) & 15 & 15 & 15 & 15 & 16 & 16 \\
\hline $\begin{array}{l}\text { Regelmatig in ploegendienst } \\
\text { werken (\% ja) }\end{array}$ & 12 & 13 & 12 & 12 & 13 & 13 \\
\hline Bron: NEA 2005-2010. & & & & & & \\
\hline
\end{tabular}

\section{Tabel 7}

Trends in ploegendienst in Nederland en in Europa

\begin{tabular}{lllll}
\hline & 1995 & 2000 & 2005 & 2010 \\
\hline Nederland & 9 & 12 & 12 & 7 \\
Mannen & 10 & 12 & 11 & 6 \\
Vrouwen & 8 & 12 & 13 & 8 \\
EU-15 & 13 & 19 & 16 & 16 \\
Mannen & 13 & 19 & 16 & 16 \\
Vrouwen & 12 & 18 & 16 & 16 \\
\hline Bron: EWCS; http://www.eurofound.europa.eu/surveys/smt/ewcs/results.htm. &
\end{tabular}

Het percentage Nederlandse werknemers dat in de EWCS aangeeft in ploegendienst te werken is wat lager dan het gemiddelde percentage van Europa (zie tabel 7). Mannen en vrouwen werken ongeveer even vaak in ploegendienst.

\section{RISICOSECTOREN}

Uit de NEA 20Io-gegevens blijkt dat in de sectoren horeca, gezondheids- en welzijnszorg en vervoer en communicatie het werken op afwijkende werktijden het meest voorkomt (zie tabel 8). In deze sectoren wordt het vaakst in ploegendienst gewerkt en 's avonds of 's nachts en in het weekend. Daarnaast worden in de horeca en in de sector vervoer en communicatie de meeste overuren gemaakt. In de sectoren bouwnijverheid en industrie is de gemiddelde omvang van het dienstverband het grootst.

\section{CONCLUSIE EN BESCHOUWINGEN}

Gegevens van de NEA wijzen uit dat werknemers die structureel overwerken of in ploegendienst werken vaker aangeven dat ze emotioneel uitgeput zijn en vaker overgewicht/obesitas hebben. Daarnaast geven ze, net als werknemers die 's avonds of 's nachts werken, vaker aan dat ze te maken hebben met arbeidsongevallen, vaker familie- of gezinsactiviteiten verwaarlozen door het werk, en werkzaamheden te missen of te verwaarlozen door familie- en gezinsverantwoordelijkheden. Gegevens van de NEA wijzen uit dat ruim een kwart van de Nederlandse werknemers structureel overwerkt, terwijl nagenoeg een kwart regelmatig 's avonds of 's nachts werkt. Verder geeft $\mathrm{I} 6 \%$ aan in ploegendienst te werken. Onder Nederlandse werknemers worden geen opvallende trends gezien in het werken op afwij-

\section{Tabel 8}

Afwijkende werktijden naar sector

\begin{tabular}{|c|c|c|c|c|c|c|c|c|c|}
\hline \multicolumn{10}{|c|}{ Afwijkende werktijden naar sector } \\
\hline & 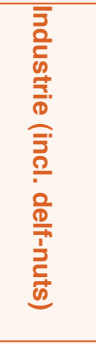 & 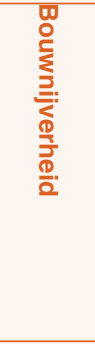 & 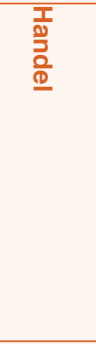 & 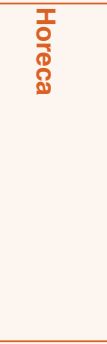 & 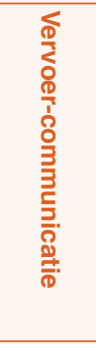 & 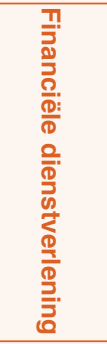 & 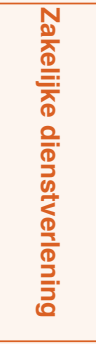 & 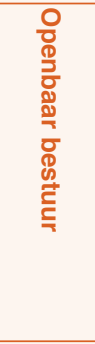 & 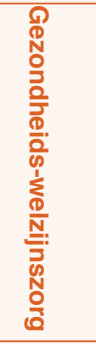 \\
\hline $\begin{array}{l}\text { Omvang dienstverband } \\
\text { Ploegendienst }\end{array}$ & 35,0 & 37,7 & 27,7 & 23,1 & 33,7 & 33,9 & 32,3 & 34,3 & 25,3 \\
\hline $\begin{array}{l}\text { Ja, regelmatig } \\
\text { 's Avonds of 's nachts }\end{array}$ & $18,3 \%$ & $2,2 \%$ & $10,0 \%$ & $23,8 \%$ & $21,8 \%$ & $1,1 \%$ & $7,6 \%$ & $12,3 \%$ & $27,1 \%$ \\
\hline $\begin{array}{l}\text { Ja, regelmatig } \\
\text { Weekend }\end{array}$ & $21,3 \%$ & $6,7 \%$ & $24,6 \%$ & $57,0 \%$ & $37,3 \%$ & $11,7 \%$ & $17,5 \%$ & $19,8 \%$ & $37,9 \%$ \\
\hline Ja, regelmatig & $20,6 \%$ & $10,5 \%$ & $42,0 \%$ & $73,5 \%$ & $41,2 \%$ & $10,0 \%$ & $18,5 \%$ & $19,4 \%$ & $43,4 \%$ \\
\hline Overuren per week & 3,39 & 3,16 & 3,25 & 4,07 & 5,59 & 3,34 & 3,37 & 2,65 & 2,81 \\
\hline
\end{tabular}


kende werktijden. Het percentage Nederlandse werknemers dat overwerkt, 's avonds/'s nachts of in het weekend werkt of in ploegendienst werkt, is over de jaren heen redelijk stabiel. Wel verschilt Nederland enigszins van gemiddeld Europa. Bij Nederlandse werknemers ligt het percentage dat minstens een keer per maand meer dan tien uur op een dag werkt, hoger dan bij de gemiddelde Europese werknemer. Het percentage Nederlandse werknemers dat aangeeft in ploegendienst te werken, is juist wat lager dan het gemiddelde percentage van Europa. Sectoren waar het werken op afwijkende werktijden vooral speelt zijn de horeca, de gezondheids- en welzijnszorg en de sector vervoer en communicatie. In het andere artikel in dit themanummer is in de conclusies al ingegaan op de rol van de Arbeidstijdenwet, de toepassing van onderzoeksresultaten op het gebied van afwijkende werktijden en de nieuwe ontwikkelingen rond zelfroosteren als mogelijkheid voor werkgevers en werknemers om de nadelige invloed van afwijkende werktijden op de veiligheid, de gezondheid en welzijn van werknemers terug te dringen. Er zijn daarnaast nog diverse andere mogelijkheden voor preventie. Dat kan op verschillende manieren, op zowel collectief, bedrijfs- als individueel niveau. Op collectief niveau kunnen de sociale partners (werkgeversorganisaties en vakbonden) afspraken maken over het verbeteren van de werktijden. Dat kan in de CAO, maar ook bijvoorbeeld via het aangeven van preventiemogelijkheden in de Arbocatalogus. Het is vaak niet nodig om tot de uiterste grenzen te gaan van de Arbeidstijdenwet. Er bestaan allerlei regels voor gezond en productief roosteren en sociale partners kunnen daarover collectief maatwerk afspraken maken die passen bij de situatie in de sector. Bovendien kunnen werkgevers en werknemers bij de sociale partners terecht voor advies over gezondere werktijden.

Op bedrijfsniveau is het van belang om gezonde en productieve roosters te maken voor de organisatie. Te veel overwerk of nachtwerk schaadt de gezondheid van werknemers en heeft dus een nadelige invloed op de productie. Er zijn veel mogelijkheden om de roosters in een onderneming te verbeteren, zonder dat dit de inzet van personeel vermindert. Van belang is dan om de bedrijfsprocessen onder de loep te nemen. In veel bedrijven zijn de bedrijfsprocessen in de loop van de tijd veranderd, maar zijn de roosters hetzelfde gebleven. Het is dan vaak nuttig om ook de roosters aan te passen, maar pas nadat ook andere mogelijkheden voor een flexibele personele inzet zijn nagegaan. Zo kunnen bijvoorbeeld pieken en dalen in het werkaanbod ook opgelost worden door het inzetten van werknemers van andere afdelingen of door afspraken te maken met uitzendbureaus. Adviesbureaus kunnen bij deze taak helpen en met een frisse blik van buiten tot oplossingen komen die de werkgever en de werknemers in het bedrijf niet meer zien.

Op individueel niveau gebeurt het al vaak dat werknemers met klachten of werknemers die reintegreren na een ziekteperiode tijdelijk op lichtere werkzaamheden worden ingezet. Lichter werk kan ook zijn dat tijdelijk geen avond- of nachtdiensten worden gedraaid. Uit gegevens van de NEA 20Io blijkt dat er bij 3,I\% van de werknemers in de afgelopen 12 maanden aanpassingen zijn verricht in de werktijden. ${ }^{4}$

Ook bij het door laten werken van werknemers tot hun $65^{\mathrm{e}}$ levensjaar of in de toekomst tot hun $67^{\mathrm{e}}$ levensjaar kan het van belang zijn om de werktijden aan te passen. Meer dan 60\% van de werknemers van 45 jaar en ouder zegt dat minder uren of minder dagen in de week werken kan bijdragen aan het in staat zijn om tot een hogere leeftijd door te werken. ${ }^{4}$

Er zijn dus veel mogelijkheden om de werktijden in organisaties aan te passen, maar het is niet zo dat afwijkende werktijden ook volledig uitgebannen kunnen worden. Een flink aantal werkprocessen in onze samenleving en economie vereist dat er ook in de nacht gewerkt wordt. Van een grote toename van het werken op afwijkende tijden door de toenemende globalisering en de technologische ontwikkelingen die 'Het Nieuwe Werken' mogelijk maken is echter geen sprake. Veel meer is een sluipend gevaar dat werknemers door de nieuwe ICT-mogelijkheden hun werk mee naar huis nemen en 's avonds en in het weekend blijven doorwerken, met de daaraan gerelateerde gevolgen van vermoeidheid en van een verstoring van het privéleven. Het blijft dus verstandig om als werkgever en werknemers waakzaam te zijn en te zorgen dat werknemers optimaal kunnen werken, ook op afwijkende tijden.

\section{LITERATUUR}

I. Zwieten M van, Houtman I, Klein Hesselink J. Impact van afwijkende werktijden: wat weten we vanuit de wetenschappelijke literatuur? Tijdschr Bedrijfs Verzekeringsgeneeskd 20II, I9: 436-445.

2. Koppes LLJ, Vroome EMM de, Mol MEM, et al. Nationale Enquête Arbeidsomstandigheden 20I0: Methodologie en globale resultaten. Hoofddorp: TNO, 20I I (te downloaden van: www.tno.nl/nea).

3. Parent-Thirion A, Fernández Macías E, Hurley J, Vermeylen G. Fourth European Working Conditions Survey. Dublin: European Foundation for the Improvement of Living and Working Conditions, 2007.

4. Hooftman W, Koppes L, Vroome E de, et al. NEA 20Io: Vinger aan de pols van werkend Nederland. Hoofddorp: TNO, 20Io (te downloaden van: www.tno.nl/ nea). 